\title{
Genomic Instability during Early Differentiation of Embryonic Stem Cells
}

\section{Clara I Esteban-Pérez ${ }^{1,2 *}$, Harold H Moreno-Ortiz ${ }^{1,2}$, Nancy A Reichert ${ }^{1}$ and Dwayne A Wise ${ }^{1}$}

${ }^{1}$ Department of Biological Sciences, Mississippi State University, Mississippi State, MS, 39762, USA

${ }^{2}$ Department of Reproductive Genetics, Colombian Center of Fertility and Sterility, CECOLFES, Bogotá, Colombia, South America

\begin{abstract}
Objective: Understanding how genomic instability could be involved in the regulation and establishment of cell lineage commitment during embryonic stem cell differentiation would provide crucial knowledge of stem cell biology. The aim of this study was to determine novel molecular biomarkers located near embryonic developmental genes responsible for embryonic stem cell signals that govern in vitro early cell fate decisions.
\end{abstract}

Methods: Analysis of genomic instability in 63 single tandem repeats markers from embryoid bodies at 7,14 and 30 days of culture samples from $\mathrm{H} 1$ and $\mathrm{H} 7$ embryonic stem cell lines. Mutation frequencies were determined using SP-PCR software from M.D. Anderson Cancer Center. Differences in mutation frequencies were calculated with a two tailed t-test with a $\mathrm{p} \leq 0.05$.

Results: We determined that the mean values of instability frequencies in embryoid bodies from two different embryonic stem cells lines showed significant differences across time between them. Different markers became unstable during spontaneous differentiation showed higher instability frequencies: one marker associated with pluripotency, nine markers with differentiation, and eight markers with imprinting. Genomic instability influences the loss of pluripotency and the gain of cell lineage specialization. Interestingly, the differentiation potential of embryoid bodies from the two stem cell lines varied. Embryoid bodies from $\mathrm{H} 1$ were prone to neuroectoderm differentiation in comparison to those from $\mathrm{H} 7$, which showed functional differentiation into mesoderm (contractile cardiac muscle).

Conclusion: We suggest that genomic instability in repetitive regions could be a signal for cell fate decision during differentiation among embryonic stem cell lines. Our results indicate correlation of instability in specific markers located near developmental genes and epigenetic modulators in embryoid bodies that underwent spontaneous differentiation in vitro. The significance of elucidating possible molecular mechanisms of genomic instability and validation of novel biomarkers could potentially support the use of embryonic stem cell are safe source for clinical applications.

Keywords: Embryonic stem cells; Cell lineage; Cell differentiation; Early cell fate; Genomic instability; pluripotency; Stem cell signaling; Embryoid body

\section{Introduction}

Embryonic stem (ES) cells are derived from the inner cell mass of a blastocyst after the first differentiation stage during embryonic development. During this stage, the embryo loses totipotency and displays pluripotent characteristics that ensure its potential for differentiation into the three germinal cell layers [1,2]. ES cells can differentiate into all cell types of the embryo by spontaneous differentiation in vitro into embryoid bodies (EB). Colonies of ES cells can be cultured in suspension with conventional ES cell culture techniques in a medium supplemented with serum containing many undefined growth factors that induce differentiation into EB. Differentiation into EB is a spontaneous process that always displays a heterogeneous mix of cell populations and is a technique to demonstrate the pluripotency capacity of the ES cells to differentiate into all three germinal layers $[1,3]$. However, these protocols are inappropriate for obtaining large numbers of homogeneous and pure cell type populations that are needed for cell regeneration treatments of human diseases.

Conditions for culture establishment and maintenance are a constant scientific challenge to improve the methodology used for this therapeutic aim. Determination and validation of precise growth factors that direction of ES cell specialization towards a homogeneous population of a selected germinal layer such as ectoderm for neurons, endoderm for pancreatic cells, or mesoderm for cardiac muscle cells still is a work in progress. Several approaches have been reported for supplementing media with specific exogenous growth factors that direct ES cell differentiation to induce mature specialized cell types, such as noggin factor that induces neural lineage commitment, activin A that induces definitive endoderm, and bone morphogenic protein (BMP) plus activin A that induce mesoderm differentiation into early cardiac muscle cells [4-9].

Differentiation is a constant process of gene modification and chromatin regulation that is responsible for the specific signals that induce morphological and functional changes in early cell progenitor derivatives during embryonic development [10]. Differentiation reflects the alteration of balance between ES cell pluripotency and self-renewal. ES cells that differentiate lose pluripotency and gain the lineage-specific signature that displays specific cell tissue identity through gene and chromatin modification in the promoter regions of developmental genes responsible for pluripotency and early cell differentiation [11]. Identification of the molecular switches that regulate differentiation of early cell progenitors could be used as a tool for target ES cell pluripotency and achieve differentiation homeostasis.

*Corresponding author: Clara I Esteban-Pérez, B.Sc, M.Sc, Ph.D, Colombian Center of Fertility and Sterility, CECOLFES, Calle 102 \#14A15. Bogotá, Colombia, South America, Tel: 571-7420505; Fax 571-7422235; E-mail: genetica@cecolfes.com

Received January 28, 2016; Accepted February 20, 2016; Published February 29,2016

Citation: Esteban-Pérez $\mathrm{Cl}$, Moreno-Ortiz HH, Reichert NA, Wise DA (2016) Genomic Instability during Early Differentiation of Embryonic Stem Cells. J Stem Cell Res Ther 6: 329. doi:10.4172/2157-7633.1000329

Copyright: () 2016 Esteban-Pérez $\mathrm{Cl}$, et al. This is an open-access article distributed under the terms of the Creative Commons Attribution License, which permits unrestricted use, distribution, and reproduction in any medium, provided the original author and source are credited. 
Pluripotency, self-renewal, and differentiation signals in ES cells naturally occur as a result of extracellular environmental stimuli. Regulation of these specific cellular signals during ES cell maintenance in vitro contributes to correct cell fate decisions [12]. Genetic and environmental changes influence the phenotype of the ES cell lines. It is important to fully characterize ES cell lines for comparative analyses in order to completely define their identity. Precise and well standardized biomarkers are needed to characterize ES cells at molecular and functional levels to ensure their quality and efficiency for cellular transplant and organ regeneration applications. In addition, this will be a crucial tool for basic embryonic development, drug testing, toxicology, and tumorigenesis research.

Several studies reported successful EB formation from ES cell lines through spontaneous differentiation into the three germinal layers. Gene expression and epigenetic pattern characteristics that underline differentiation of ES cell lines in vitro have been widely reported [1317]. However, the precise molecular signals that coordinate ES cell differentiation are not completely understood. Identification of unstable repetitive sequences of the DNA is a sensitive molecular technique to evaluate DNA integrity of ES cells. ES cells in culture acquire different genetic and epigenetic modifications in order to maintain pluripotency or induce ES cell differentiation into the functional phenotype of lineage specific neuroectoderm, mesoderm, or endoderm cell layers $[3,16,18]$.

We determined the genomic instability during spontaneous differentiation of EB from H1 and H7 ES cell lines. EB samples were obtained at three time points of EB progression at 7, 14, and 30 days after differentiation induction. The frequency of genomic instability in 63 single tandem repeat markers located near pluripotency, differentiation, and imprinting genes was determinate by calculating the instability frequency of each sample per marker. The aim of this study was to determine novel molecular biomarkers for monitoring ES cell signals that govern differentiation in vitro. We report that genomic instability could be the signal that leads to ES cell differentiation through modulation of gene expression and epigenetic modifications during cell lineage and tissue derivation of cell populations in EBs from $\mathrm{H} 1$ and H7 ES cell lines. Finally, determination of reported single tandem repeat stability offers a mechanism for characterization as well as defining new protocols for directing ES cell differentiation in vitro towards particular cell lineages that are needed for clinical applications.

\section{Materials and Methods}

\section{Embryonic stem cell culture conditions}

Frozen aliquots from human ES cells H1-WA01 passage 27 and H7-WA07 passage 26 were purchased from the National Stem Cell Bank-Wisconsin International Stem Cell Bank. H1 and H7 ES cells were seeded onto a mouse embryo fibroblast-CF1 (MEF) feeder layer previously inactivated with mitomicyn $\mathrm{C}$. The culture medium consisted of Dulbecco's Modified Eagle Medium (DMEM) knockout medium (Invitrogen, Carlsbad, CA) supplemented with $10 \%$ knockout serum replacement (Invitrogen, Carlsbad, CA), 1\% antibiotic-antimycotic (Invitrogen, Carlsbad, CA), $2 \mu \mathrm{g} / \mathrm{ml}$ basic fibroblast growth factor (b-FGF) (Invitrogen, Carlsbad, CA ), 1\% non-essential amino acids (Invitrogen Carlsbad, CA), and $100 \mathrm{mM} \mathrm{L}$-glutamine (Invitrogen, Carlsbad, CA) plus $\beta$-mercaptoethanol (Sigma Aldrich Saint Louis, $\mathrm{MO}$ ). ES cells were maintained in a humidified atmosphere at $37^{\circ} \mathrm{C}$ in $5 \% \mathrm{CO}_{2}$. The medium was changed daily.

\section{Embryoid body formation}

For in vitro differentiation of ES cells through embryoid body formation, undifferentiated ES cell colonies at 3-5 days post-passage, maintained on a mouse embryo fibroblast (MEF) feeder layer during 15 passages for both ES cell lines, were mechanically dissociated and transferred into a low attachment petri dish containing embryoid body (EB) medium. EB medium consisted of Dulbecco's Modified Eagle Medium (DMEM) knockout medium (Invitrogen, Carlsbad, CA) supplemented with $20 \%$ fetal calf serum (Invitrogen, Carlsbad, CA), 1\% L-glutamine (Invitrogen, Carlsbad, CA), 1\% non essential amino acids (NEAA) (Invitrogen, Carlsbad, CA), and $0.1 \mathrm{mM}$ $\beta$-mercaptoethanol (Sigma, Aldrich Saint Louis, MO). EBs were cultured in suspension for 5 days with medium changes every other day. Then, EBs were transferred to $60 \mathrm{~mm}$ center-well culture dishes (Corning Incorporated, Corning, NY) previously coated with $0.1 \%$ gelatin (Sigma, Aldrich Saint Louis, MO) and cultured for 30 days with $\mathrm{EB}$-medium in a humidified atmosphere at $37^{\circ} \mathrm{C}$ and $5 \% \mathrm{CO}_{2}$. During the 30 day culture period, medium was renewed every 2 days, but less frequent medium changes were made depending on EB culture density. Samples of EBs in culture were collected at 7, 14, and 30 days for histopathology, immunohistochemical, and molecular analysis.

\section{Histopathology}

EBs were harvested and fixed with formalin (Sigma-Aldrich, Saint Louis, MO) overnight at room temperature, washed in 1X PBS, dehydrated with an ethanol wash, and embedded in paraffin. The $5 \mu \mathrm{m}$ thick sections from the paraffin embedded EBs were placed on slides. After deparaffinization of the slide by xylene, alcohol, and water washes, slides were stained with hematoxylin-eosin for routine histological examination under microscope.

\section{Immunohistochemical analysis}

EB samples attached to gelatin were fixed with $4 \%$ paraformaldehyde (Sigma-Aldrich, Saint Louis, MO) for 15 minutes at room temperature, washed in 1X PBS, and immunostained (Miltenyi Biotec Inc, Auburn, CA). The primary antibodies used were rabbit anti-GATA4 polyclonal antibody (endoderm), anti-myosin heavy chain monoclonal antibody (mesoderm), and anti- $\beta$-III Tubulin clone AA2 alexa fluor 488 conjugated mouse monoclonal antibody (ectoderm) (Chemicon/ Millipore Billerica, MA). Antigen detection was performed with secondary antibodies; goat-anti-rabbit IgG rhodamine and C5Y conjugated secondary antibody (Chemicon/Millipore Billerica, MA). Each antibody was diluted to 1:200 in 1 XPBS with $0.1 \%$ Triton X-100 and 3\% BSA. Nuclei were visualized with 4'-6-diamidino-2-phenylindole (DAPI) staining (Vysis Abbott Laboratories, Abbott Park, IL). EBs stained without the primary antibody served as a negative control. Images were captured using a fluorescence microscope, Axiovert 135, (Carl Zeiss International), with a FITC and Rhodamine filter set. Fluorescent intensities were measured with a semi quantitative method using image software developed at the National Institute of Health (Bethesda, MD, USA). Accumulation of fluorescence was calculated by averaging the fluorescent ratio between exposed and unexposed areas in the nuclei.

\section{DNA isolation}

DNA was prepared from each sample of EBs $(7,14,30$ days of differentiation induction) that were previously collected in $1 \mathrm{X}$ PBS by mechanical disruption in pieces under a stereomicroscope. Samples from EBs and cell suspensions were isolated with the Purelink ${ }^{\text {tw }}$ genomic DNA mini-kit (Invitrogen Carlsbad, CA) following the manufacturer's protocol. All DNA samples were quantified using a NanoDrop ${ }^{\mathrm{mm}}$ ND1000 spectrophotometer (Thermo Scientific, Wilmington, DE). 


\section{Determination of genomic instability with single cell PCR}

Analysis of genomic instability of all DNA samples (listed previously) was carried out using 63 STR markers. 11 markers were located near promoters of pluripotency genes, 32 markers were related to differentiation genes, and 20 markers were related to imprinting genes (Table 1). Total reaction volume of fluorescent multiplex PCR reactions was $10 \mu$ containing $1 \mathrm{X}$ of $10 \mathrm{X}$ buffer $\mathrm{D}, 2.5 \mathrm{mM}$ of $\mathrm{MgCl}_{2}$ $1.25 \mathrm{U}$ of Hot-MultiTaq DNA polymerase, 1X of Solution L (these four reagents are from US DNA, Fort Worth, TX), 4\% of DMSO (Sigma Aldrich, Saint Louis, MO), $0.4 \mathrm{mg} / \mathrm{ml}$ of BSA (Thermo Scientific, Rockford, IL), $300 \mu \mathrm{M}$ of dNTPs (Applied Biosystems, Foster City, $\mathrm{CA}$ ), and primer sets at a final concentration ranging between $0.2-2$ $\mu \mathrm{M}$ (Supplementary Table 1). Each replicate contained $9 \mu \mathrm{l}$ of master mix with $1 \mu \mathrm{l}$ of DNA at a concentration of less than a single diploid genome-equivalent $(25-50 \mathrm{pg} / \mu \mathrm{l})$. This DNA concentration allowed detection of wild type and mutant alleles in the same replicate [19]. 48 replicates for each marker and each sample with appropriate negative controls were amplified. PCR was performed on a PE 9600 thermocycler using a ramping protocol: 1 cycle of $95^{\circ} \mathrm{C}$ for 11 minutes; 1 cycle of $96^{\circ} \mathrm{C}$ for 1 minute; 10 cycles of $\left[94^{\circ} \mathrm{C}\right.$ for 30 seconds, ramp 68 seconds to $58^{\circ} \mathrm{C}$ (hold for 30 seconds), ramp 50 seconds to $70^{\circ} \mathrm{C}$ (hold for 60 seconds)]; 25 cycles of $\left(90^{\circ} \mathrm{C}\right.$ for 30 seconds, ramp 60 seconds to $58^{\circ} \mathrm{C}$ (hold for 30 seconds), ramp 50 seconds to $70^{\circ} \mathrm{C}$ (hold for 60 seconds)); 1 cycle of $60^{\circ} \mathrm{C}$ for 30 minutes for final extension for adenine addition; and hold $4^{\circ} \mathrm{C}$. Negative controls without DNA were included to check for contamination.

Fluorescent PCR products $(0.5 \mu \mathrm{l})$ were denatured in formamide $(4.35 \mu \mathrm{l})$ (Applied Biosystemss, Foster City, CA) and size standard Genescan 500-LIZ (0.15 $\mu \mathrm{l})$ (Applied Biosystemss, Foster City, CA), to be detected by capillary electrophoresis on an AB3130xl Genetic Analyzer (Applied Biosystemss, Foster City, CA). Fragment size of alleles was estimated by GeneMapper software version 4.0 (Applied Biosystemss Foster City, CA). In each single cell replicate the allele size was compared and scored with the internal lane size standard. 48 replicates per sample and negative controls were amplified and scored for both ES cell lines samples.

\section{Statistical analysis of genomic instability}

Mutation frequencies were determined using SP-PCR software version 1.0 (M.D. Anderson Cancer Center Houston, TX). Differences in mutation frequencies were calculated with a two tailed t-test using raw mutation frequencies in the statistical package SAS/win 9.2 (SAS Institute, Cary, NC) to determine statistically significant differences ( $p$-value $\leq 0.05)$ in the mean mutation frequencies of informative markers. Marginally significant differences were considered if the p-value $\leq 0.10$.

\section{Results}

\section{ES cells spontaneously differentiate into embryoid bodies in vitro}

ES cell pluripotency is evaluated by the efficiency with which they form EBs and drive ES cell differentiation into the three germinal layers symmetrically and spontaneously upon removal the MEF feeder layer, and supplementing of the medium with $20 \%$ fetal calf-serum $[5,20]$. Initially, our EBs developed compact and tri-dimensional cell aggregates in suspension during the first 7 days. Once they attached, EB aggregates began to spread and display an irregular shape distribution. This was indicative of differentiation into a heterogeneous mix of cell populations derived from the three germinal layers from day 7 to day 30 after induction of EB differentiation. Microscopic morphology of EBs was determined with stained paraffin-embedded sections. The EB morphology showed stratified keratinizing epithelium (characteristic of ectoderm), cardiac muscle (characteristic of mesoderm), and pseudostratified columnar epithelium (characteristic of endoderm) (Figure 1). The morphology, coupled with the expression of specific immunofluorescence markers ( $\beta$-III tubulin-ectoderm, Myosinmesoderm, and GATA4-endoderm), confirmed that $\mathrm{H} 1$ and $\mathrm{H} 7 \mathrm{ES}$ cell lines maintained the capacity for spontaneous differentiation into EBs that display a mixed population of cells from the three germinal layers during in vitro culturing (Figure 2).

\section{Genomic instability is present during ES cells differentiation in vitro}

During early determination of cell fate, genes responsible for cell differentiation are activated and pluripotency genes are turned off. The molecular mechanisms that induce these gene expression changes are unclear [21]. The aim of this study was to determine if genomic instability was present at this time and could possibly be a signal of ES cells' spontaneous differentiation. ES cells that efficiently differentiate into EBs were evaluated for genomic instability with 63 single tandem repeat markers at three time points $(7,14$, and 30 days) after EBs culture establishment were analyzed. Significant mean frequencies of instability in 18 out of 63 markers were detected. Markers located near differentiation and imprinting genes displayed higher instability frequencies compared to markers located near pluripotency genes. Only one marker located near a pluripotency gene showed significant instability (D1S551). In comparison, nine markers located near differentiation genes were significantly unstable (D16S3034, D16S3090, D14S588，D11S4090，D3S1583，D1S468，DXS1208，D4S2623, and

\begin{tabular}{|c|c|c|c|c|}
\hline Pluripotency & \multicolumn{3}{|c|}{ Differentiation } & Imprinting \\
\hline OCT 4 & D16S3034 & D6S1698 & D16S3091 & D7S488 \\
\hline D1S1656 & D12S1719 & D10S1653 & D1S468 & D6S1001 \\
\hline D1S551 & D4S2623 & D11S909 & TNFa3 & HISTH4A \\
\hline D12S1682 & D2S134 & D5S2021 & D15S983 & HISTHB2 \\
\hline D1S2630 & D11S1331 & D18S63 & DXS1208 & D10S529 \\
\hline D6S2384 & D4S1625 & D4S1542 & D5S426 & D22S447 \\
\hline D6S416 & D1S430 & DXS981 & D3S1541 & D8S11268 \\
\hline D2S2327 & D2S290 & D14S588 & G60405 & D22S941 \\
\hline NANOG & D3S1583 & D3S2459 & D3S1611 & D7S638 \\
\hline D9S1840 & DXS458 & D17S2180 & D11S2179 & D6S2252 \\
\hline & D21S1909 & EGFR & & D2S144 \\
\hline
\end{tabular}

Table 1: List of single tandem repeat markers analyzed in samples of embryoid bodies from $\mathrm{H} 1$ and $\mathrm{H} 7 \mathrm{ES}$ cell lines. Ten markers were related to pluripotency genes, 33 were related to differentiation genes, and 20 were related to imprinting genes. 
A

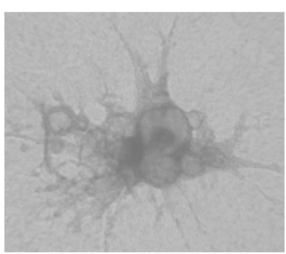

B

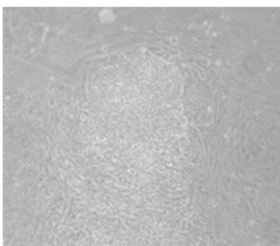

C

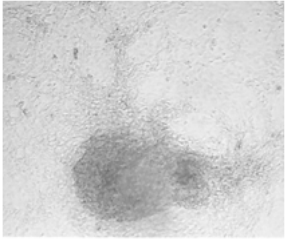

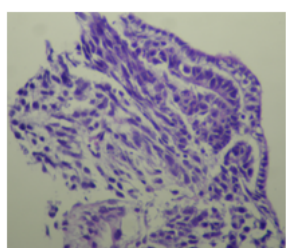
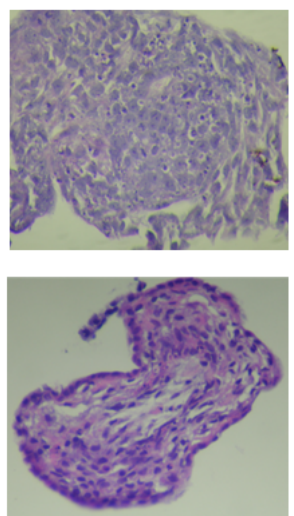

Figure 1: Histological characterizations of embryoid bodies from ES cells.

$A, B$, and $C$ are from EBs at 14 days after in vitro differentiation showing typical morphology and histology characteristics of differentiated tissues from the three germinal layers. (A) Neural epithelium characteristics in an ectoderm layer. (B) Mesenchymal characteristics in a mesoderm layer. (C) Pseudostratified columnar epithelium characteristics in an endoderm layer. Phase contrast images (left panels) are shown with 10X magnification. Haematoxylin and Eosin stained images (right panels) are shown at 60X magnification.

A
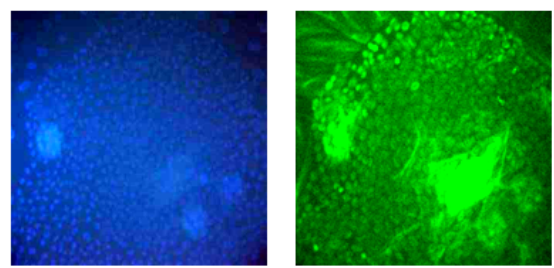

B
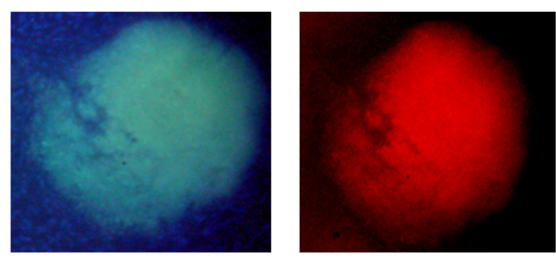

C
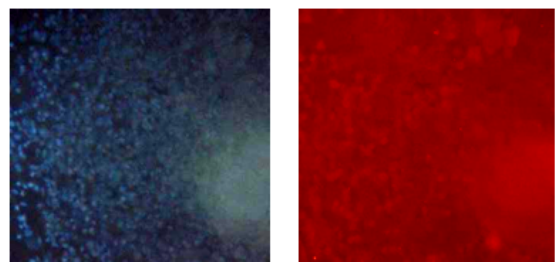

Figure 2: Immunofluorescent characterization of embryoid bodies differentiated from ES cells.

$A, B$, and $C$ are from EBs at 14 days after in vitro differentiation. (A) EB showing BIIl-tubulin positive expression (green) which is characteristic of neuroectoderm differentiation. (B) EB showing myosin positive expression (red) which is characteristic of cardiac muscle (mesoderm differentiation). (C) EB showing GATA positive expression (orange) which is characteristic of endoderm differentiation. Nuclei were visualized with DAPI stain (blue) (left panels). Fluorescence images are show in magnification of $60 \mathrm{X}$.
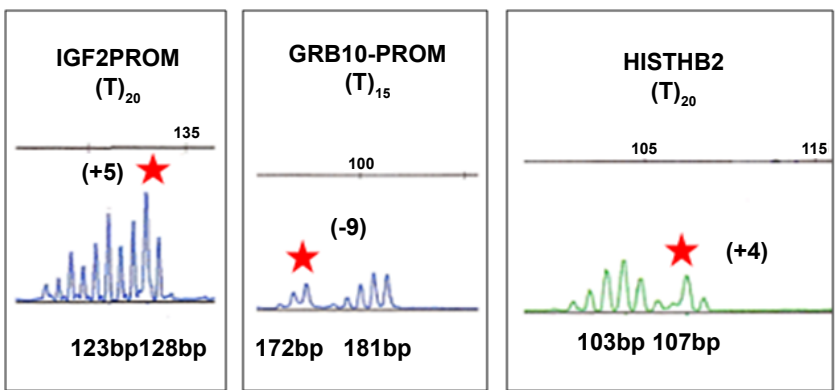

Figure 3A: Examples of electropherograms from mononucleotide unstable markers.

Normal and mutated alleles are identified according to repeat motif shifts. Mononucleotide markers (IGF2-PROM, GRB10-PROM, and HISTBH2) show the corresponding normal allele, as well as the mutated allele that was shifted greater than 3 or less than 3 repeats motifs. Mutated alleles are indicated with a red star and the number of repeat motif shifts is in parentheses. (-) indicated a loss of repeat units, while $(+)$ indicated a gain of repeat units. Normal alleles are shown next to their mutated alleles. Each set of peaks is identified by the marker name and repeat motif (top row). Shown below each peak is the size of each allele in base pair (bp). Markers were labeled with either 6-FAM (blue) or HEX (green) fluorescent dyes.

D18S63), and eight markers related to imprinting were significantly unstable (IGF2PROM, GRB10PROM, HISTHB2, D6S2252, D2S144, D3S1611, D7S488, and D10S529) (Figures 3A-3D). These results show that genomic instability was detected in specific single tandem repeat markers during EB differentiation and could be determinate signals for ES cell fate specialization.

Single tandem repeat instability increased during EB formation over time

ES cell differentiation occurs in a spontaneous multistep manner, which results in cell specialization. We found significant differences in genomic instability among EBs from $\mathrm{H} 1$ and $\mathrm{H} 7 \mathrm{ES}$ cell lines over time. At 30 days post differentiation, EB samples were significantly unstable in comparison to EBs from 7 and 14 days. Instability frequencies at day 30 were increased two-fold in comparison with the earlier frequencies (day 7). EBs from $\mathrm{H} 1$ showed an instability mutation frequency of 0.018 at 7 days and 0.039 at 30 days, whereas EBs from the $\mathrm{H} 7$ showed an instability frequency of 0.016 at 7 days and 0.036 at 30 days $(\mathrm{p}<0.05)$ (Figure 4). EBs from $\mathrm{H} 1$ show an increased number of unstable markers $(n=18)$ time in comparison to EBs from $\mathrm{H} 7(\mathrm{n}=14)$. HISTHB2, IGF2PROM, and D3S1583 were unstable markers at 7 days of EB culture. In contrast, markers that were unstable at 14 days included D18S63, D3S1611, D6S2252, HISTHB2, D16S3034, and D3S1583. At 30 days unstable markers: D1S468, DXS1208, D2S144, GRB10PROM, D7S488, D4S2623, D10S529, D16S3090, IGF2PROM, D11S4090, and D14S588 (Figure 4). These observations confirmed that spontaneous differentiation occurred at the same time that genomic instability increased during EB formation. Therefore, genomic instability could potentially drive differentiation progression in vitro.

\section{Embryoid bodies from $\mathrm{H} 1$ and $\mathrm{H} 7 \mathrm{ES}$ cell lines show different unstable marker profiles}

During the last decade, complete gene expression profiles have been reported for ES cells. Gene expression modifications are due to ES cell culture maintenance in vitro $[21,22]$. The aim of this study was to determining whether EBs from $\mathrm{H} 1$ and $\mathrm{H} 7 \mathrm{ES}$ cell lines would show instability in the same markers. Our study reports that eight markers showed increased instability in markers for EBs of both ES 


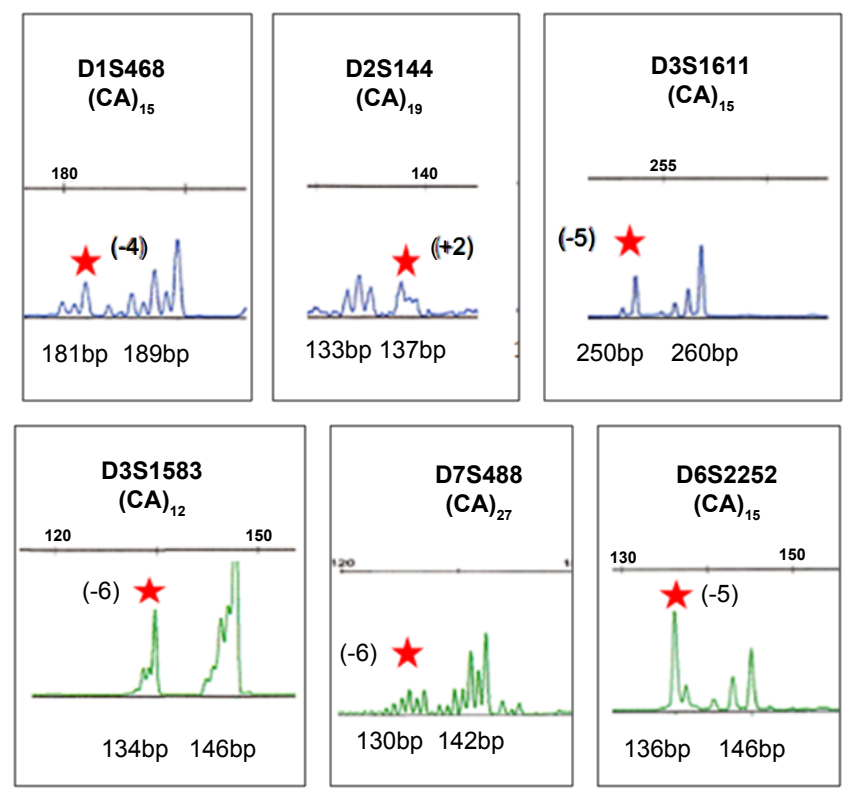

Figure 3B: Examples of electropherograms from dinucleotide unstable markers.

Normal and mutated alleles are identified according to repeat motif shifts. Dinucleotide markers (D1S468, D2S144, D3S1611, D13S1583, D6S2252, and D7S488) show the corresponding normal allele, as well as the mutated allele that was shifted greater than 2 or less than 3 repeat motifs. Mutated alleles are indicated with a red star and the number of repeat motif shifts is in parentheses. (-) indicated a loss of repeat units, while (+) indicated a gain of repeat units. Normal alleles are shown next to their mutated alleles. Each set of peaks is identified by the marker name and repeat motif (top row). Shown below each peak is the size of each allele in base pair (bp). Markers were labeled with either 6-FAM (blue) or HEX (green) fluorescent dyes.

cell lines (D16S3034, D10S529, D14S588, D16S3091, IGF2PROM, D11S4090, D3S1583, and D1S551) (Figure 5 and Supplementary Table 2). EBs from $H 1$ showed the highest significant mean frequencies of instability in seven additional markers (D1S468, DXS1208, D2S144, GRB10PROM, D18S563, D3S1611, and D7S488) ( $\mathrm{p} \leq$ 0.05) (Figure 6 and Supplementary Table 3) whereas, EBs from H7 showed instability in only three additional markers (HISTHB2, D6S2252, and D4S2623) $(\mathrm{p} \leq 0.05)$ (Figure 6 and Supplementary Table 4). Notably, unstable markers in EB from $\mathrm{H} 1$ were located near genes involved in early neuroectodermal differentiation. In contrast, EBs from $\mathrm{H} 7$ displayed instability in markers located near genes involved in mesodermal and endodermal differentiation. EBs from both $\mathrm{H} 1$ and H7 ES cell lines showed instability in markers related to imprinting genes. Taken together these results confirm that ES cells showed differential profiles of unstable markers during EB differentiation in vitro.

Instability in repetitive regions related to differentiation genes coordinate cell fate decisions

Upon progression of differentiation, gene modifications act as signals that facilitate cell fate decisions [23-25]. We searched for possible associations between genomic instability of specific markers and the differentiation preferences of individual ES cell lines. We characterized our ES cell lines by morphologic and genomic instability patterns throughout EB differentiation in vitro. EBs from $\mathrm{H} 1$ and H7 ES cell lines showed mixed populations of cells after 30 days of culturing in EB media supplemented with fetal calf serum. However, we observed that multiple neural rosette like neuroectoderm structures were more common in $\mathrm{EB}$ cultures from $\mathrm{H} 1$ when compared to
EBs from H7 (Figure 7). This is positively correlated with instances of instability that showed increased mean frequencies for markers specific to the neuroectoderm layer (D11S4090, D3S1583, D1S468,

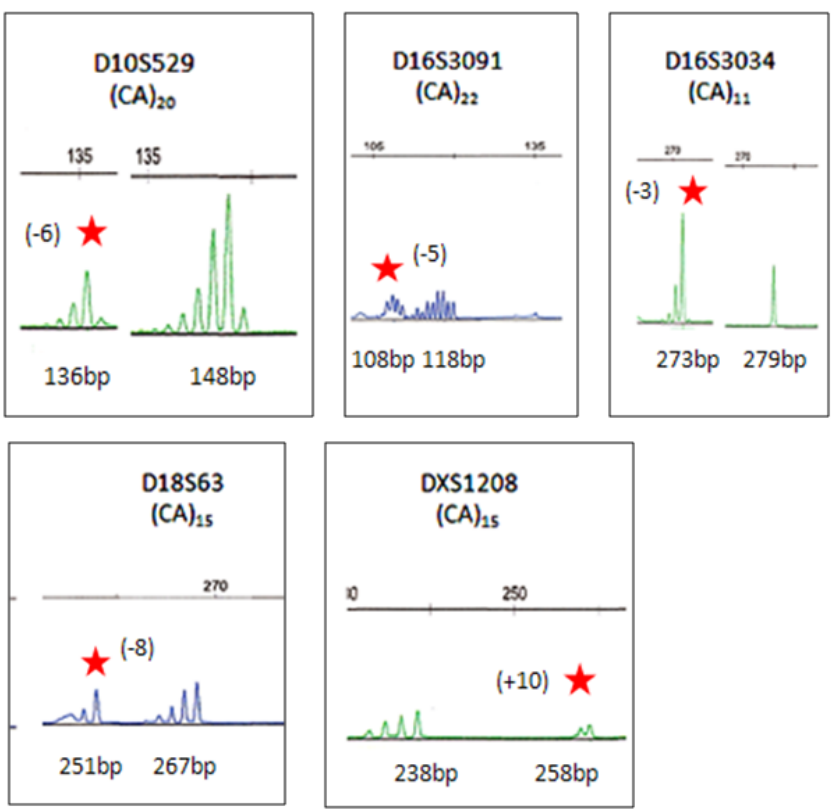

Figure 3C: Examples of electropherograms from dinucleotide unstable markers.

Normal and mutated alleles are identified according to repeat motif shifts. Dinucleotide markers (D10S529, D16S3034, D16S3091, D18S63, and DXS1208) show the corresponding normal allele, as well as the mutated allele that was shifted greater than 2 or less than 3 repeat motifs. Mutated alleles are indicated with a red star and the number of repeat motif shifts is in parentheses. (-) indicated a loss of repeat units, while $(+)$ indicated a gain of repeat units. Normal alleles are shown next to their mutated alleles. Each set of peaks is identified by the marker name and repeat motif (top row). Shown below each peak is the size of each allele in base pair (bp). Markers were labeled with either 6-FAM (blue) or HEX (green) fluorescent dyes.

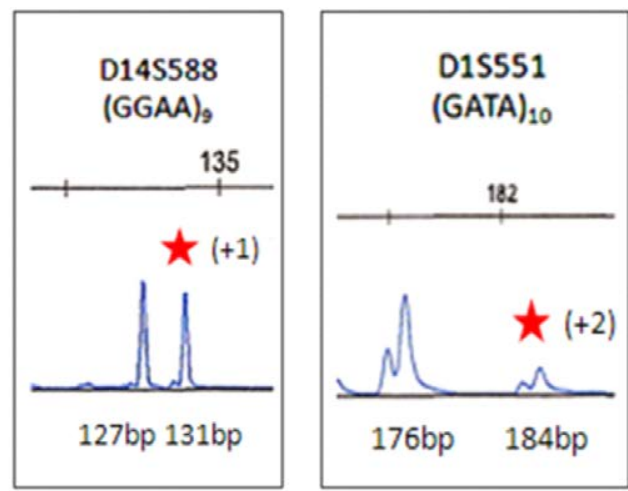

Figure 3D: Examples of electropherograms from tetranucleotide unstable markers.

Normal and mutated alleles are identified according to repeat motif shifts. Tetranucleotide markers (D14S588 and D1S551) show the corresponding normal allele, as well as the mutated allele that was shifted greater than 1 or less than 2 repeat motifs. Mutated alleles are indicated with a red star and the number of repeat motif shifts is in parentheses. (-) indicated a loss of repeat units, while $(+)$ indicated a gain of repeat units. Normal alleles are shown next to their mutated alleles. Each set of peaks is identified by the marker name and repeat motif (top row). Shown below each peak is the size of each allele in base pair (bp). Markers were labeled with 6-FAM (blue) fluorescent dyes. 
A

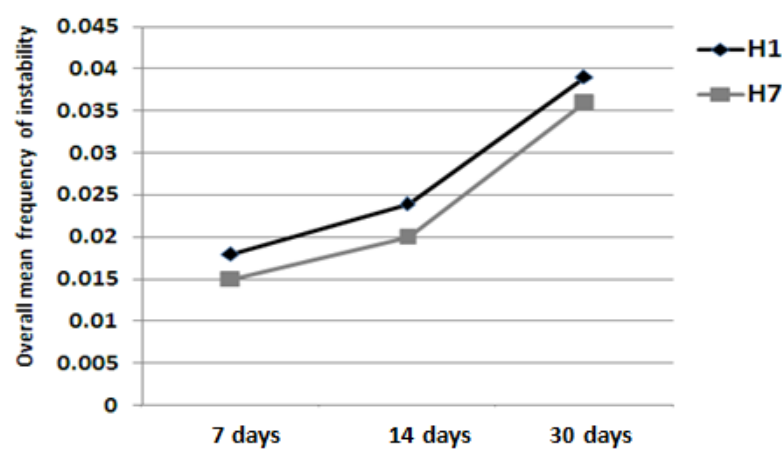

B

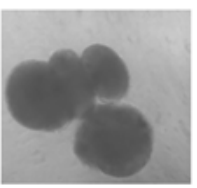

C

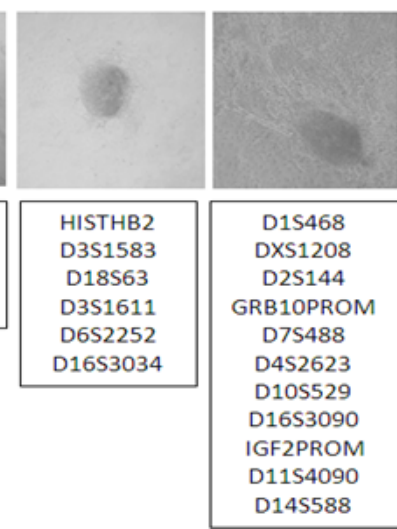

Figure 4: Mean mutation frequencies of unstable markers across EB samples at three points of time.

(A) EBs from $\mathrm{H} 1$ and $\mathrm{H} 7$ ES cell lines showed statistically significant differences of frequencies of unstable markers at 7 days after in vitro differentiation when compared to frequencies of unstable markers at 30 days after in vitro differentiation $(p<0.05)$. Values represent the overall mean frequency of unstable markers over three points of time. (B) Phase contrast image of EBs in suspension at 7,14 , and 30 days after in vitro differentiation (magnification of 10X) (C) List of unstable markers at 7, 14, and 30 days after in vitro differentiation

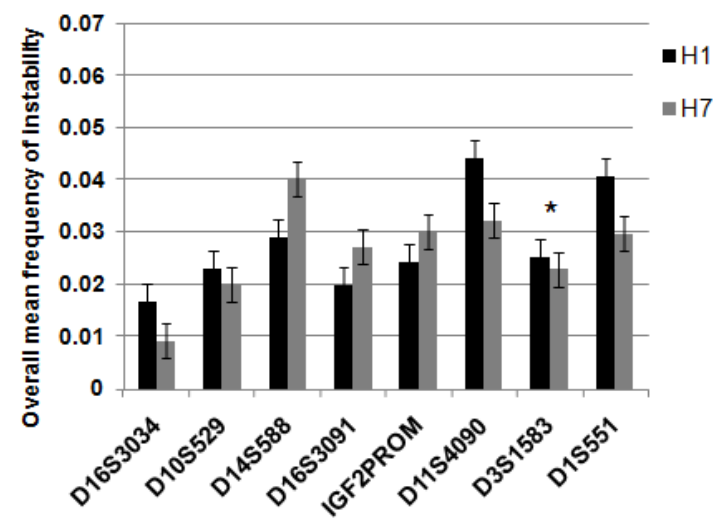

Figure 5: Unstable markers in embryoid bodies differentiated from $\mathrm{H} 1$ and $\mathrm{H} 7$ ES cell lines.

Differences in overall mean mutation frequencies were observed between EBs from $\mathrm{H} 1$ and $\mathrm{H} 7 \mathrm{ES}$ cell lines. Values represent the overall mean mutation frequency of EB sample replicates $(n=144)$ per marker that was calculated with SP-PCR software (MD Anderson Cancer Houston, TX). D16S3091 and IGF2-PROM markers showing a highly statistically significance differences $(p<0.001)$. D16S3034, D10S529, D14S588, D11S4090, and D1S551 markers show high statistically significant differences $(p \leq 0.05)$. The D3S1583 marker did not show any significance differences $\left({ }^{*}\right)$.
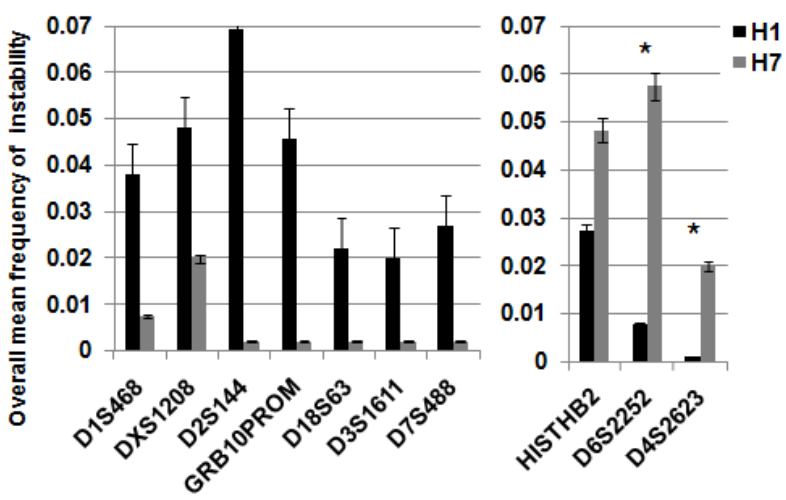

Figure 6: Unstable markers of embryoid bodies differentiated from $\mathrm{H} 1$ and H7 ES cell lines.

Statistically significant differences in overall mean mutation frequencies were observed between EBs from $\mathrm{H} 1$ and $\mathrm{H} 7 \mathrm{ES}$ cell lines. (A) Overall mean values for mutation frequencies of unstable markers observed in EBs from the $\mathrm{H} 1$ $\mathrm{ES}$ cell line. (B) Overall mean values for mutation frequencies of unstable markers observed in EBs from the H7 ES cell line. Values represent the overall mean mutation frequency of EB sample replicates $(n=144)$ per marker that was calculated with SP-PCR software (MD Anderson Cancer Houston, TX). Markers show statistically significant differences $p \leq 0.05$ except for D6S2252 and D4S2623 that show marginally significant differences ${ }^{*} \mathrm{p} \leq 0.10$.

DXS1208, and D18S63). In contrast, EBs from H7 showed instability in markers related to mesoderm (D14S588 and D16S3091) [26,27], and endoderm differentiation (D4S2623) (Table 2). In addition, EBs from $\mathrm{H} 7$ showed morphological and functional spontaneous differentiation into contracting EBs, increased cell confluency, as well as increased contraction rates in the developing EBs (Figure 8). Our results show that instability in repetitive regions near genes responsible for early cell differentiation of neuroectoderm and mesoderm were not equally regulated between differentiation of $\mathrm{H} 1$ and $\mathrm{H} 7 \mathrm{ES}$ cell lines in vitro.

\section{Epigenetic modification during spontaneous EB differentiation a result from genomic instability}

Early embryonic differentiation signals are regulated by epigenetic changes such as imprinting, chromatin changes, and methylation [2830]. We found that specific markers related to imprinting showed increased frequencies of instability during EB differentiation from both ES cell lines. Markers associated with tissue specific imprinting genes (IGF2, and GRB10), histone genes (HISTHB2, D6S2252, D7S488, and D10S529), de novo methylation genes (D2S144), and DNA repair genes (D3S1611) showed significant differences in instability in EB from $\mathrm{H} 1$ and $\mathrm{H} 7 \mathrm{ES}$ cell lines. Markers located in the promoter regions of the genes IGF2 and GRB10 displayed highly significant instability $(\mathrm{p}<0.001)$. The marker near IGF2 was unstable in EBs from both the $\mathrm{H} 1$ and H7, with the highest instability frequency found in EBs from the H7. The marker in GRB10 however, was exclusively unstable in EBs from the H1. Additionally, D2S144 was significantly, and exclusively, unstable in EBs from $\mathrm{H} 1$ ( $\mathrm{p}=0.0081)$ compared with EBs from the H7 that were stable. D10S529 was unstable in EBs from both ES cell lines but was highly significantly unstable in EBs from the H1 compared with EB from H7 ( $p=0.0308)$. Together, these findings demonstrate that instability as a molecular signaling pathway might control the epigenetic changes necessary to induce gene expression changes in ES cells that are undergoing early progenitor differentiation.

\section{Discussion}

Understanding the molecular signals that regulate the decisions 

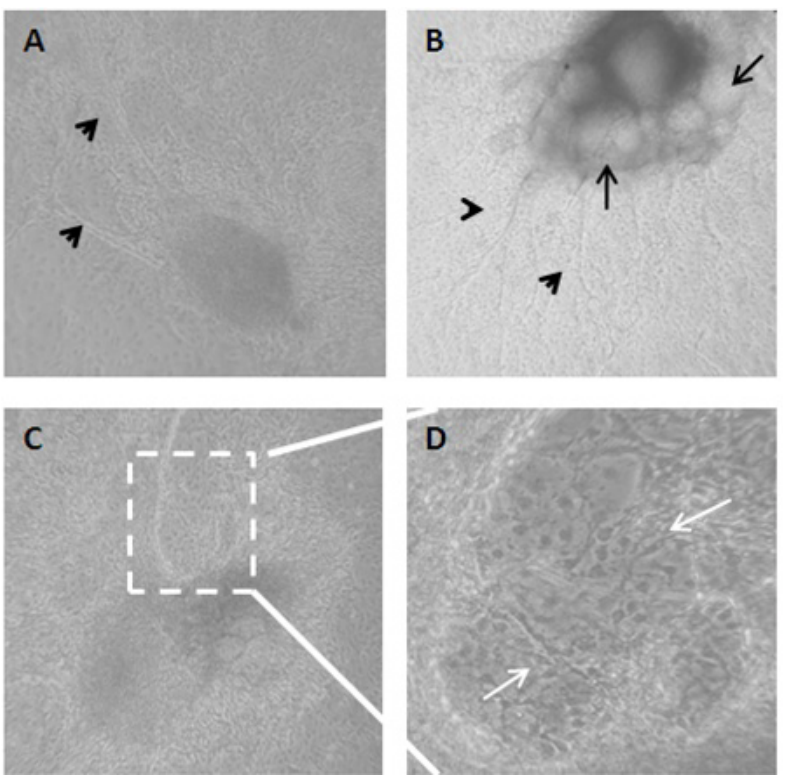

Figure 7: Embryoid bodies from the H1 ES cell line differentiated into early neuroectodermal tissue after 30 days.

(A-B) Neural progenitor spheres with extensive cell growth around the clusters and neurite grew radially from the middle EB sphere (black arrow heads). (B) Neural rosettes are observed inside the floating spheres (black arrows). (C) Neural rosette with high confluence of early progenitors that appear after 3 weeks of in vitro differentiation from the H1 ES cell line. (D) Boxed region from $\mathrm{C}$ panel, shown in 60X magnification and displays neuronal generation in the outgrowth area. Cells generated are in migration status (white arrows). Phase contrast images $(\mathrm{A}-\mathrm{C})$ are at a magnification of $10 \mathrm{X}$.

\begin{tabular}{|c|c|c|c|c|}
\hline STR & Gene & Gene Name & Gene Function & References \\
\hline D16S3034 & CHD9 & $\begin{array}{c}\text { Chromodomain helicase } \\
\text { DNA binding protein 9 }\end{array}$ & $\begin{array}{c}\text { Embryo } \\
\text { development }\end{array}$ & Shur I, 2006 \\
\hline D10S529 & H2AFY2 & $\begin{array}{c}\text { H2A histone family, } \\
\text { member Y2 }\end{array}$ & $\begin{array}{c}\text { Nucleosome } \\
\text { assembly }\end{array}$ & Mathew J, 2010 \\
Marcus B, 2009 \\
\hline D14S588 & PTGDR & $\begin{array}{c}\text { Prostaglandin D2 } \\
\text { receptor (DP) } \\
\text { transduction } \\
\text { regulator }\end{array}$ & Boie Y, 1995 \\
\hline D16S3091 & CDH13 & $\begin{array}{c}\text { Cadherin 13, } \\
\text { H-cadherin (heart) }\end{array}$ & $\begin{array}{c}\text { Growth factor } \\
\text { activity }\end{array}$ & Li L, 2010 \\
\hline IGF2PRO & IGF2 & $\begin{array}{r}\text { Insulin-like growth factor } \\
\text { 2 (Somatomedin A) }\end{array}$ & $\begin{array}{c}\text { Growth factor } \\
\text { activity }\end{array}$ & $\begin{array}{l}\text { Tabano S, 2010 } \\
\text { Demars J, 2010 }\end{array}$ \\
\hline D11S4090 & NCAM & $\begin{array}{r}\text { Neural cell adhesion } \\
\text { molecule 1 }\end{array}$ & $\begin{array}{c}\text { Signal } \\
\text { transduction } \\
\text { regulator }\end{array}$ & Kleene R, 2010 \\
\hline D3S1583 & RARB & $\begin{array}{c}\text { Retinoic acid receptor, } \\
\text { bet }\end{array}$ & $\begin{array}{c}\text { Embryo } \\
\text { development }\end{array}$ & $\begin{array}{l}\text { Elizalde C, 2011 } \\
\text { Sheng N, 2010 }\end{array}$ \\
\hline D1S551 & RGS4 & $\begin{array}{r}\text { Regulator of G-protein } \\
\text { signaling 4 }\end{array}$ & $\begin{array}{c}\text { Signal } \\
\text { transduction } \\
\text { regulator }\end{array}$ & $\begin{array}{l}\text { Charlesworth P, } \\
\text { 2006 Ebert PJ, } \\
\text { 2006 }\end{array}$ \\
\hline D1S468 & TP73 & Tumor protein p73 & $\begin{array}{r}\text { Transcription } \\
\text { factor }\end{array}$ & $\begin{array}{l}\text { Berna S, 2010 } \\
\text { Kim KP, 2007 }\end{array}$ \\
\hline
\end{tabular}

Table 2: List of genes associated with unstable markers.

Summary of gene characteristics located in close proximity to unstable markers involved in embryonic development. These eighteen unstable markers were identified in EBs differentiated from $\mathrm{H} 1$ and $\mathrm{H} 7 \mathrm{ES}$ cell lines.

determining ES cell fates in vitro during early progenitor differentiation can help identify reliable genetic markers that will be useful for characterizing the mix of cell populations obtained from the three germinal layers. Careful characterization of ES cells and their celltype specific outcomes serve to validate them for prospective clinical applications that would require specific ES cell progenies isolated from spontaneous differentiation protocols in vitro. We evaluated single tandem repeat markers located near embryonic developmental genes related to pluripotency, differentiation, and imprinting of ES cells, to determine their stability during spontaneous differentiation of EBs in vitro.

Normally, ES cells can differentiate into a heterogeneous mixed population of EB cell types from the three germinal layers in vitro. EBs can be differentiated into a wide variety of cell types that are functionally equivalent to in vivo tissues $[5,20]$. We hypothesized that instability in repetitive sequences located near important genes responsible for cell differentiation could control the subsequent cell fate decisions during the progression of differentiation.

Differentiation is a process where pluripotency of the ES cells is lost through embryogenesis. ES cells differentiate progressively until they achieve complete cell specialization and functional cell-tissue capacities $[24,25]$. Our results show that EBs undergoing differentiation accumulates instability in different markers located near possible target genes that are responsible for early cell differentiation and imprinting. This is consistent with our results that just one pluripotency marker was unstable in comparison with nine unstable markers related to differentiation, and eight unstable markers related to imprinting during EB culturing. Our data suggest that some pluripotency genes still act upon progression of differentiation until complete cell lineage commitment is achieved. In addition, the observation of progressive instability in markers located near differentiation and imprinting genes could be the signals of specific cell fate decisions that are required for each ES cell line.

First, ES cells undergoing differentiation need intracellular and extracellular signals that vary over time that regulate the transcriptional factor machinery. This induces cell type specific changes through completion of lineage commitment [31-33]. During differentiation induction in vitro, our EBs showed increased cell density after 20 days in culture. We observed high instability frequencies in EB samples at 30 days of culture. At that time, maximum efficiency in cell to cell interaction and cell differentiation was observed, and the confluence of EBs from $\mathrm{H} 1$ and $\mathrm{H} 7 \mathrm{ES}$ cell lines was almost 100\%. Our data support the affirmation that differentiation is a dynamic process where interaction between cells and addition of chemical supplements to the culture medium can drive ES cells toward differentiation in addition
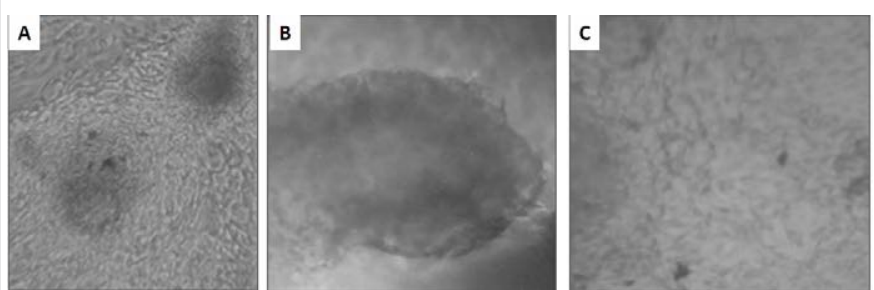

Figure 8: Embryoid bodies from the H7 ES cell line differentiated into cardiac muscle tissue (early mesoderm) 14 days after in vitro differentiation induction.

(A) EBs differentiated into mesoderm, showing characteristic morphology of a confluent cardiac lineage. (B-C) EBs differentiated into functional mesoderm, showing contractile cardiac muscle. Contraction rate frequency increased over time during in vitro differentiation. (B) Initially, the rate was 50 contractions per minute $(\mathrm{cpm})$ at 14 days of in vitro differentiation induction (see supplemental file Video005). (C) Contractions increased to $70 \mathrm{cpm}$ after 30 days of in vitro differentiation induction (see supplemental file Video007). Phase contrast images are at a magnification of $10 \mathrm{X}$. 
to playing an important role in inducing molecular signals needed to obtain specialized cell types.

Second, developmental genes are responsible for controlling differentiation in ES cells. Molecular markers located near specific genes could be good candidates for the evaluation of cell fate progression during embryogenesis. We found significant instability frequencies in 18 single tandem repeat markers localized near developmental genes. Our results support the idea that these markers are possible target sequences responsible for the molecular signals of pluripotency, differentiation, and imprinting during ES cell commitment specialization of lineage in vitro. We found important correlations between genes in close proximity to the unstable markers analyzed in this study. For example, POU family transcription factor (POUF) is a regulator of pluripotency that prevents ES cell differentiation. Repression of this gene induces ES cell differentiation into primitive endoderm [10,24]. D1S551 is a marker located near the POUF gene and was significantly unstable later in the EB formation process ( 30 day sample), indicating that instability acts as a signal to silence this pluripotency gene, and allows progression of differentiation of the ES cells. On the other hand, genomic instability in repetitive regions could be required for selective preference of differentiation into the three germinal layers during EB progression in H1 and H7 ES cells. In our study, signaling pathways that control spontaneous $\mathrm{EB}$ differentiation in $\mathrm{H} 1$ and $\mathrm{H} 7$ in vitro reveal differences in the capacity to achieve homogeneous cell populations at the end of differentiation. EBs from $\mathrm{H} 1$ and $\mathrm{H} 7$ did not differentiate equally well into the three germinal layers. EBs from $\mathrm{H} 1$ efficiently promoted more neuroectoderm structures in comparison to EBs from $\mathrm{H} 7$ that efficiently promoted more mesoderm structures as a functional cardiac muscle cells. Our observations suggest that $\mathrm{H} 1$ and $\mathrm{H} 7 \mathrm{ES}$ cell lines show specific embryonic differentiation patterns. Interestingly, EBs from $\mathrm{H} 1$ and $\mathrm{H} 7$ show different molecular patterns of instability. Significant differences within unstable markers were observed and could be the source of differences in the noted cell morphological and functional characteristics. EBs from $\mathrm{H} 1$ were unstable for markers related to early neuroectoderm differentiation. For example, D1S468 is located near tumor protein p53 (TP73) gene, which is involved in the cellular stress response and development. Deletion of this gene is involved in neuroblastoma [34]. DXS1208 is located near the heat shock $27 \mathrm{kDa}$ protein $\beta 1$ (HSP25/27) gene implicated in astrocytic and cortical degeneration $[35,36]$. D18S63 is located near the TGF $\beta$-induced factor homeobox 1 (TGIF1), a transcription regulator during development, and is associated with structural brain abnormalities [37-39]. D11S4090 is located near the gene neural cell adhesion molecule 1 (NCAM) that is necessary for the induction of synaptic plasticity in the hippocampus [40]. D3S1583 is located near the retinoic acid receptor beta (RARB) gene, which is a developmental gene responsible for cell growth and differentiation [41,42]. Additionally, EBs from $\mathrm{H} 1$ and $\mathrm{H} 7 \mathrm{ES}$ cell lines showed instability in markers involved in mesoderm differentiation. For example, D16S3034 is located near the chromodomain helicase DNA binding protein 9 (CHD9) gene that is involved in early osteogenic cell differentiation [43]. D16S3091 is located near cadherin $13 \mathrm{H}$-cadherin (CDH13) gene that is a mediator of cell-cell interaction in the heart and negative regulator of neural cell growth [27].

Third, epigenetic modifications are necessary to induce gene expression changes in ES cells undergoing differentiation into early progenitor cell types of the three germinal layers (ectoderm, endoderm, and mesoderm). Chromatin modification is a mechanism that potentially drives cell fate decisions, cell renewal, and lineage specialization. Improper silencing or activation of specific genes induces chromatin remodeling modifications $[3,18,21,24]$. Changes in chromatin structure can regulate commitment specialization of ES cell lineage by modulating gene expression through two ways namely modification of histones and second and methylation of promoters regulating specific developmental genes. These modifications ensure the expression or repression of target genes during cell differentiation. However, it is not fully understood how these steps are coordinated. Previous studies have confirmed that histone modifications are associated with transcriptionally active regions in the genome that regulate spontaneous differentiation of ES cells in vitro [21,44]. ES cells that failed to keep their repressive chromatin and lost the capacity to differentiate into the three germinal layers [3,29]. Consequently, histone $\mathrm{H} 2 \mathrm{~A}$ ubiquitination reduction and histone $\mathrm{H} 3$ and $\mathrm{H} 4$ acetylation enrichment modifications allow gene transcription to maintain ES cell pluripotency $[28,45]$. Our results suggest that instability in repetitive regions near histone specific genes could be a signal for histone modification that generates repressive or active chromatin to modulate gene expression during cell lineage commitment. From our results, four significant unstable markers that showed high instability are related to the histone genes HISTHB2 and D6S2252 (HIST1H2AH), both of which are linker histones responsible for chromatin compaction $[38,46,47]$. Another histone gene, D10S529 (H2AFY2), is involved in inactivation of the $\mathrm{X}$ chromosome [48,49]. All three markers were especially significant in the instability detected in EBs from H7 ES cell line when compared to EBs from H1. Studies have reported changes in $\mathrm{X}$ inactivation in female ES cells, which was congruent with our results because the H7 ES cell line is female [48,50]. Marker D7S488 located near the histone deacetylase 9 isoform 3 (HDAC) gene is responsible for tissue-specific gene expression during cell differentiation [51]. We found that this marker was exclusively unstable in EBs from $\mathrm{H} 1$. Taken together, our results suggest that instability in these sequences, which are near specific histone genes, could be a signal for chromatin modifications that repress expression of pluripotency genes during spontaneous differentiation.

In addition to chromatin modification by histones, methylation of gene promoter regions is responsible for establishing the epigenetic changes that allow for the pluripotency or differentiation status of ES cells. DNA (cytosine-5)-methyltransferases (DNMT) catalyze the addition of methyl groups to the cytosines in CpG islands that are located in promoter regions of genes, and they are responsible for controlling access of transcription factors to the genome [52]. Changes in methylation during differentiation have been widely reported [53,54], supporting the idea that methylation is a key gene regulator of the pathway leading to ES cell fate decisions. D2S144 is located near the DNA (cytosine-5)-methyltransferase 3 alpha gene (DNMT3A) responsible for de novo DNA methylation during embryonic development, and displays significant instability $[55,56]$. DNMT3A de novo methylation in ES cell lines induces silencing in pluripotency and self-renewal genes in the differentiated cells and prevents de-differentiation or reactivation of pluripotency in somatic adult tissues [53]. Methylation is the mechanism for gene imprinting during early embryonic development. We also observed significant unstable markers located in promoter regions of two genes that are imprinted in tissue specific manner. Growth factor receptor-bound protein 10 (GRB10) gene is imprinted in the paternal allele in the brain and is responsible for modulation of tyrosine kinase activity. GRB10 overexpression results in suppression of embryonic growth [57,58]. Insulin-like growth factor 2 (IGF2) gene, expressed only from the paternal allele, is involved in embryonic development and growth $[59,60]$. Therefore, epigenetic modifications have two essential functions, regulating cell fate decisions during stages of differentiation and preserving the cell specialization status throughout the cell's life. 
Finally, identification of specific target sequences that are predominantly unstable during spontaneous differentiation might provide clues to deciphering molecular mechanisms used to express and/or repress genes during embryogenesis and cell lineage commitment. In addition, our results reveal a novel molecular tool for characterizing cell populations according to their genomic integrity through analysis of unstable markers located near important genes responsible for early cell differentiation. This novel tool has potential significance and practical applications for use in regenerative medicine. To our knowledge, this study is the first to identify potentially useful biomarkers that can determine the stability of specialized cell populations differentiated in vitro from ES cells. Further evaluation of these markers will enable more precise characterizations of ES cells and cell populations during development, so their applications could be fully assessed.

\section{Acknowledgements}

We would like to thank the National Stem Cell Bank for providing the $\mathrm{H} 1$ (WA01) and H7 (WA07) human embryonic stem cell lines. I would like to thank the following: Dr. Nancy Reichert, Dr. Janet Donaldson, and Kortney Wilkinson for manuscript editing; Dr. Jim Cooley and Stephany Mays for the embryoid bodies' histological analysis; William Monroe and Amanda Lawrence for his assistance with confocal microscopy and image capture. This research was funded by the Department of Biological Sciences, Office of Institutional Research, Graduate school Office, and the College of Art and Sciences at Mississippi State University

\section{References}

1. Thomson JA, Itskovitz-Eldor J, Shapiro SS, Waknitz MA, Swiergiel JJ, et al. (1998) Embryonic stem cell lines derived from human blastocysts. Science 282: 1145-1147. [PubMed]

2. Chen $X, X u H$, Yuan $P$, Fang $F$, Huss $M$, et al. (2008) Integration of external signaling pathways with the core transcriptional network in embryonic stem cells. Cell 133: 1106-1117. [PubMed]

3. Enver T, Soneji S, Joshi C, Brown J, Iborra F, et al. (2005) Cellular differentiation hierarchies in normal and culture adapted human embryonic stem cells. Hum Mol Genet 14: 3129-3140. [PubMed]

4. Ben-Hur T, Idelson M, Khaner H, Pera M, Reinhartz E, et al. (2004) Transplantation of human embryonic stem cell-derived neural progenitors improves behavioral deficit in Parkinsonian rats. Stem Cells 22: 1246-1255. [PubMed]

5. D'Amour KA, Bang AG, Eliazer S, Kelly OG, Agulnick AD, et al. (2006) Production of pancreatic hormone expressing endocrine cells from human embryonic stem cells. Nat Biotechnol 24: 1392-1401. [PubMed]

6. Jiang J, Au M, Lu K, Eshpeter A, Korbutt G, et al. (2007) Generation of insulinproducing islet-like clusters from human embryonic stem cells. Stem Cells 25: 1940-1953. [PubMed]

7. Yao S, Chen S, Clark J, Hao E, Beattie GM, et al. (2006) Long-term self-renewal and directed differentiation of human embryonic stem cells in chemically defined conditions. Proc Natl Acad Sci U S A 103: 6907-6912. [PubMed]

8. Yang L, Yang XC, Yang JK, Guo YH, Yi FF, et al. (2008) Cyclosporin A suppresses proliferation of endothelial progenitor cells: Involvement of nitric oxide synthase inhibition. Intern Med 47: 1457-1464. [PubMed]

9. Zhou B, Ma Q, Rajagopal S, Wu SM, Domian I, et al. (2008) Epicardial progenitors contribute to the cardiomyocyte lineage in the developing heart. Nature 454: 109-113. [PubMed]

10. Niwa H, Toyooka Y, Shimosato D, Strumpf D, Takahashi K, et al. (2005) Interaction between Oct $3 / 4$ and $\mathrm{Cd} \times 2$ determines trophectoderm differentiation. Cell 123: 917-929. [PubMed]

11. Mohn F, Weber M, Rebhan M, Roloff TC, Richter J, et al. (2008) Lineagespecific polycomb targets and de novo DNA methylation define restriction and potential of neuronal progenitors. Mol Cell 30: 755-766. [PubMed]

12. Niwa $H$ (2007) Open conformation chromatin and pluripotency. Genes Dev 21: 2671-2676. [PubMed]

13. Brimble SN, Zeng X, Weiler DA, Luo, Y, Liu Y, et al. (2004) Karyotypic stability, genotyping, differentiation, feeder-free maintenance, and gene expression sampling in three human embryonic stem cell lines derived prior to August 9 , 2001. Stem Cells Dev 13: 585-597. [PubMed]

14. Ware CB, Nelson AM, Blau CA (2006) A comparison of $\mathrm{NIH}$-approved human ESC lines. Stem Cells 24: 2677-2684. [PubMed]

15. International Stem Cell Initiative, Adewumi O, Aflatoonian B, Ahrlund-Richter L, Amit M, et al. (2007) Characterization of human embryonic stem cell lines by the International Stem Cell Initiative. Nat Biotechnol 25: 803-816. [PubMed]

16. Allegrucci C, Wu YZ, Thurston A, Denning CN, Priddle H, et al. (2007) Restriction landmark genome scanning identifies culture induced DNA methylation instability in the human embryonic stem cell epigenome. Hum Mo Genet 16: 1253-1268. [PubMed]

17. Osafune K, Caron L, Borowiak M, Martinez RJ, Fitz-Gerald CS, et al. (2008) Marked differences in differentiation propensity among human embryonic stem cell lines. Nat Biotechnol 26: 313-315. [PubMed]

18. Baker DE, Harrison NJ, Maltby E, Smith K, Moore HD, et al. (2007) Adaptation to culture of human embryonic stem cells and oncogenesis in vivo. Nat Biotechnol 25: 207-215. [PubMed]

19. Coolbaugh-Murphy M, Maleki A, Ramagli L, Frazier M, Lichtiger B, et al. (2004) Estimating mutant microsatellite allele frequencies in somatic cells by smallpool PCR. Genomics 84: 419-430. [PubMed]

20. Chambers I, Colby D, Robertson M, Nichols J, Lee S, et al. (2003) Functiona expression cloning of Nanog, a pluripotency sustaining factor in embryonic stem cells. Cell 113: 643-655. [PubMed]

21. Boyer LA, Lee TI, Cole MF, Johnstone SE, Levine SS, et al. (2005) Core transcriptional regulatory circuitry in human embryonic stem cells. Cell 122 947-956. [PubMed]

22. Loh YH, Wu Q, Chew JL, Vega VB, Zhang W, et al. (2006) The Oct4 and Nanog transcription network regulates pluripotency in mouse embryonic stem cells. Nat Genet 38: 431-440. [PubMed]

23. Smith A (2005) The battlefield of pluripotency. Cell 123: 757-760. [PubMed]

24. Feldman N, Gerson A, Fang J, Li E, Zhang Y, et al. (2006) G9a-mediated irreversible epigenetic inactivation of Oct-3/4 during early embryogenesis. Nat Cell Biol 8: 188-194. [PubMed]

25. Galán A, Montaner D, Póo ME, Valbuena D, Ruiz V, et al. (2010) Functional genomics of 5 - to 8-cell stage human embryos by blastomere single-cell cDNA analysis. PLoS One 5: e13615. [PubMed]

26. Boie Y, Sawyer N, Slipetz DM, Metters KM, Abramovitz M (1995) Molecular cloning and characterization of the human prostanoid DP receptor. J Biol Chem 270: 18910-18916. [PubMed]

27. Li L, Wang S, Jezierski A, Moalim-Nour L, Mohib K, et al. (2010) A unique interplay between Rap1 and E-cadherin in the endocytic pathway regulates self-renewal of human embryonic stem cells. Stem Cells 28: 247-257. [PubMed]

28. Lee TI, Jenner RG, Boyer LA, Guenther MG, Levine SS, et al. (2006) Contro of developmental regulators by Polycomb in human embryonic stem cells. Cell 125: 301-313. [PubMed]

29. Pasini D, Bracken AP, Hansen JB, Capillo M, Helin K (2007) The polycomb group protein Suz12 is required for embryonic stem cell differentiation. Mol Cell Biol 27: 3769-3779. [PubMed]

30. Christophersen NS, Helin K (2010) Epigenetic control of embryonic stem cell fate. J Exp Med 207: 2287-2295. [PubMed]

31. Snykers S, Vinken M, Rogiers V, Vanhaecke T (2007) Differential role of epigenetic modulators in malignant and normal stem cells: a novel tool in preclinical in vitro toxicology and clinical therapy. Arch Toxicol 81: 533-544. [PubMed]

32. Chowdhury F, Li Y, Poh YC, Yokohama-Tamaki T, Wang N, et al. (2010) Soft substrates promote homogeneous self-renewal of embryonic stem cells via downregulating cell-matrix tractions. PLoS One 5: e15655. [PubMed]

33. Vallier L, Alexander M, Pedersen RA (2005) Activin/Nodal and FGF pathways cooperate to maintain pluripotency of human embryonic stem cells. J Cell Sci 118: 4495-4509. [PubMed]

34. Kim KP, Thurston A, Mummery C, Ward-van Oostwaard D, Priddle H, et al. (2007) Gene-specific vulnerability to imprinting variability in human embryonic stem cell lines. Genome Res 17: 1731-1742. [PubMed] 
Citation: Esteban-Pérez Cl, Moreno-Ortiz HH, Reichert NA, Wise DA (2016) Genomic Instability during Early Differentiation of Embryonic Stem Cells. J Stem Cell Res Ther 6: 329. doi:10.4172/2157-7633.1000329

Page 10 of 10

35. Schwarz L, Vollmer G, Richter-Landsberg C (2010) The small heat shock protein HSP25/27 (HSPB1) is abundant in cultured astrocytes and associated with astrocytic pathology in progressive supranuclear palsy and corticobasal degeneration. Int J Cell Biol 717520: 1-10. [PubMed]

36. Kirbach BB, Golenhofen N (2011) Differential expression and induction of smal heat shock proteins in rat brain and cultured hippocampal neurons. J Neurosci Res 89: 162-175. [PubMed]

37. Pazmany T, Tomasi TB (2006) The major histocompatibility complex class II transactivator is differentially regulated by interferon-gamma and transforming growth factor-beta in microglial cells. J Neuroimmunol 172: 18-26. [PubMed]

38. Wang $\mathrm{H}$, Wang L, Erdjument-Bromage $\mathrm{H}$, Vidal M, Tempst $\mathrm{P}$, et al. (2004) Role of histone H2A ubiquitination in Polycomb silencing. Nature 431: 873-878. [PubMed]

39. Hamid R, Brandt SJ (2009) Transforming growth interacting factor (TGIF) regulates proliferation and differentiation of human myeloid leukemia cells. Mol Oncol 3: 451-463. [PubMed]

40. Kleene R, Mzoughi M, Joshi G, Kalus I, Bormann U, et al. (2010) NCAMinduced neurite outgrowth depends on binding of calmodulin to NCAM and on nuclear import of NCAM and fak fragments. J Neurosci 30: 10784-10798. [PubMed]

41. Sheng N, Xie Z, Wang C, Bai G, Zhang K, et al. (2010) Retinoic acid regulates bone morphogenic protein signal duration by promoting the degradation of phosphorylated Smad1. Proc Natl Acad Sci U S A 107: 18886-18891. [PubMed]

42. Elizalde C, Campa VM, Caro M, Schlangen K, Aransay AM, et al. (2011) Distinct roles for Wnt-4 and Wnt-11 during retinoic acid-induced neuronal differentiation. Stem Cells 29: 141-153. [PubMed]

43. Shur I, Solomon R, Benayahu D (2006) Dynamic interactions of chromatinrelated mesenchymal modulator, a chromodomain helicase-DNA-binding protein, with promoters in osteoprogenitors. Stem Cells 24: 1288-1293. [PubMed]

44. Azuara V (2006) Profiling of DNA replication timing in unsynchronized cell populations. Nat Protoc 1: 2171-2177. [PubMed]

45. de Napoles M, Mermoud JE, Wakao R, Tang YA, Endoh M, et al. (2004) Polycomb group proteins Ring1A/B link ubiquitylation of histone $H 2 A$ to heritable gene silencing and $X$ inactivation. Dev Cell 7: 663-676. [PubMed]

46. Zhang R, Poustovoitov MV, Ye X, Santos HA, Chen W, et al. (2005) Formation of MacroH2A-containing senescence-associated heterochromatin foci and senescence driven by ASF1a and HIRA. Dev Cell 8: 19-30. [PubMed]

47. Petty EL, Collette KS, Cohen AJ, Snyder MJ, Csankovszki G (2009) Restricting dosage compensation complex binding to the X chromosomes by H2A.Z/HTZ1. PLoS Genet 5: e1000699. [PubMed]

48. Buschbeck M, Uribesalgo I, Wibowo I, Rué P, Martin D, et al. (2009) The histone variant macroH2A is an epigenetic regulator of key developmental genes. Nat Struct Mol Biol 16: 1074-1079. [PubMed]

49. Gamble MJ, Frizzell KM, Yang C, Krishnakumar R, Kraus WL (2010) The histone variant macroH2A1 marks repressed autosomal chromatin, but protects a subset of its target genes from silencing. Genes Dev 24: 21-32. [PubMed]

50. Chadwick BP, Willard HF (2001) Histone H2A variants and the inactive $X$ chromosome: identification of a second macroH2A variant. Hum Mol Genet 10: 1101-1113. [PubMed]

51. Karamboulas C, Swedani A, Ward C, Al-Madhoun AS, Wilton S, et al. (2006) HDAC activity regulates entry of mesoderm cells into the cardiac muscle lineage. J Cell Sci 119: 4305-4314. [PubMed]

52. Jaenisch R, Bird A (2003) Epigenetic regulation of gene expression: how the genome integrates intrinsic and environmental signals. Nat Genet $33 \mathrm{Suppl}$ 245-254. [PubMed]

53. Lagarkova MA, Volchkov PY, Lyakisheva AV, Philonenko ES, Kiselev SL (2006) Diverse epigenetic profile of novel human embryonic stem cell lines. Cell Cycle 5: 416-420. [PubMed]

54. Meissner A, Mikkelsen TS, Gu H, Wernig M, Hanna J, et al. (2008) Genomescale DNA methylation maps of pluripotent and differentiated cells. Nature 454: 766-770. [PubMed]

55. Chen T, Ueda Y, Xie S, Li E (2002) A novel Dnmt3a isoform produced from an alternative promoter localizes to euchromatin and its expression correlates with active de novo methylation. J Biol Chem 277: 38746-38754. [PubMed]

56. Wienholz BL, Kareta MS, Moarefi AH, Gordon CA, Ginno PA, et al. (2010) DNMT3L modulates significant and distinct flanking sequence preference for DNA methylation by DNMT3A and DNMT3B in vivo. PLoS Genet 6: e1001106. [PubMed]

57. Tezuka N, Brown AM, Yanagawa S (2007) GRB10 binds to LRP6, the Wnt coreceptor and inhibits canonical Wnt signaling pathway. Biochem Biophys Res Commun 356: 648-654. [PubMed]

58. Monk D, Arnaud P, Frost J, Hills FA, Stanier P, et al. (2009) Reciprocal imprinting of human GRB10 in placental trophoblast and brain: Evolutionary conservation of reversed allelic expression. Human Molecular Genetics 18 3066-3074. [PubMed]

59. Demars J, Shmela ME, Rossignol S, Okabe J, Netchine I, et al. (2010) Analysis of the IGF2/H19 imprinting control region uncovers new genetic defects, including mutations of oct binding sequences, in patients with $11 \mathrm{p} 15$ fetal growth disorders. Hum Mol Genet 19: 803-814. [PubMed]

60. Tabano S, Colapietro P, Cetin I, Grati FR, Zanutto S, et al. (2010) Epigenetic modulation of the IGF2/H19 imprinted domain in human embryonic and extraembryonic compartments and its possible role in fetal growth restriction. Epigenetics 5: 313-324. [PubMed] 